\title{
APRENDIZAGEM BASEADA EM PROJETOS E INCENTIVO ÀS PRÁTICAS DE LEITURA
}

\author{
Mauricio Ferreira Chaves ${ }^{1}$
}

\section{RESUMO}

As práticas educativas tiveram de se adequar às demandas modernas inerentes ao novo perfil de alunado. Junto a esse movimento, surgiram teorias inovadoras que possibilitaram uma nova forma de desenvolver habilidades em sala de aula. Nesse movimento, o ato de ler também se modificou, sendo necessárias iniciativas para se manter o incentivo às práticas de leitura. Um desses caminhos é a Aprendizagem Baseada em Projetos que trouxe uma metodologia de ensino mais coadunada à realidade dos estudantes de Educação Básica, em específico. Assim, o presente estudo busca relacionar a Aprendizagem Baseada em Projetos ao incentivo às práticas de leitura ao longo da Educação Básica. Para tanto, foram consultados materiais, artigos, monografias, dissertações e teses relacionados às duas unidades de análise em questão: a Aprendizagem Baseada em Projetos e a leitura. Desse modo, espera-se com esta investigação que se destaque no meio educativo a importância de um ensino planejado e intencional no que tange ao estímulo constante por textos escritos a fim de possibilitar uma inserção de estudantes na comunidade leitora.

Palavras-chave: Práticas Educativas; Aprendizagem por Projetos; Leitura.

\section{ABSTRACT}

Educational practices had to adapt to the modern demands inherent to the new student profile. Along with this movement, innovative theories emerged that enabled a new way to develop skills in the classroom. In this movement, the act of reading has also changed, requiring initiatives to maintain the incentive to reading practices. One of these paths is project learning, which brought a teaching methodology more in line with the reality of Basic Education students, in particular. Thus, the present study seeks to relate project learning to encouraging reading practices throughout Basic Education. For that, materials, articles, monographs, dissertations and theses were consulted, related to the two units of analysis in question: project learning and reading. Thus, it is hoped with this investigation that the importance of a planned and intentional teaching with regard to the constant stimulation by written texts in order to allow the insertion of students in the reading community is highlighted in the educational environment.

Keywords: Educational Practices; Project Learning; Reading.

\section{RESUMEN}

Las prácticas educativas debían adaptarse a las exigencias modernas inherentes al nuevo perfil de los estudiantes. Junto con este movimiento, surgieron teorías innovadoras que permitieron una nueva forma de desarrollar habilidades en el aula. En este movimiento, el acto de leer también ha cambiado, requiriendo iniciativas para mantener el incentivo a las prácticas lectoras. Uno de estos caminos es el aprendizaje por proyectos, que trajo una metodología de enseñanza más acorde con la realidad de los estudiantes de Educación Básica, en particular. Así, el presente estudio busca relacionar el aprendizaje por proyectos con el fomento de las prácticas lectoras en toda la Educación Básica. Para ello se consultaron materiales, artículos, monografías, disertaciones y tesis, relacionados con las dos unidades de análisis en cuestión: aprendizaje de proyectos y lectura. Así, se espera con esta investigación que se destaque en el ámbito educativo la importancia de una enseñanza planificada e intencional en cuanto a la estimulación constante por parte de los textos escritos para permitir la inserción de los estudiantes en la comunidad lectora.

Palavras clave: Prácticas Educativas; Aprendizaje de Proyectos; Lectura.

1Possui graduação em Ciências Contábeis pela Universidade Federal Fluminense (2008); é pós-graduado em Gestão Pública Municipal pela Universidade Federal Fluminense (2012), em Gestão de Saúde Pública na UFF (2018), e em Administração Pública na UFF (2019). 


\section{INTRODUÇÃO}

A presente investigação cinge o fenômeno acerca da essencialidade do aporte da Aprendizagem Baseada em Projetos, como ainda, nas possíveis alternativas de incentivos às práticas de leitura, salientando que a situaçãoproblema se instaura em parte da sociedade por esta não ter o hábito da leitura por considerar o custo financeiro do livro alto, dificultando, assim, a sua efetividade.

O problema do ato de ler no campo educativo não é algo novo, pois os mecanismos estatísticos que mensuram o desempenho de estudantes no desenvolvimento de habilidades de leitura não revelam números promissores. $O$ último PISA - Programa Internacional de Avaliação de Estudantes, realizado a cada três anos pela Organização para a Cooperação e Desenvolvimento Econômico (OCDE), oferece informações sobre o desempenho dos estudantes na faixa etária dos 15 anos, vinculando dados sobre seus backgrounds e suas atitudes em relação à aprendizagem, e, também, os principais fatores que moldam sua aprendizagem inclusive do campo da leitura que seguem de dados referentes ao campo das ciências e da matemática (INEP, 2018).

No que tange aos níveis educacionais da área da leitura, envolvendo atividades de interpretação de diversos tipos de textos, os resultados não são considerados adequados para um país como o Brasil com dimensões continentais e com o perfil econômico que possui. Desse modo, a última edição do PISA - Programa Internacional de Avaliação de Estudantes, realizado em 2018, revelou que 50\% dos estudantes brasileiros não possuem nível básico em leitura, sendo esse o mínimo para o exercício pleno da cidadania, de acordo com as orientações da Organização para a Cooperação e Desenvolvimento Econômico (OCDE).

O gráfico a seguir traz, de modo compilado, os resultados divulgados a partir dos dados de 2018, o último exame, incluindo os números das outras áreas avaliadas, ciências e matemática (INEP, 2018). 
Gráfico 1. Dados do PISA - Programa Internacional de Avaliação de Estudantes (2018)

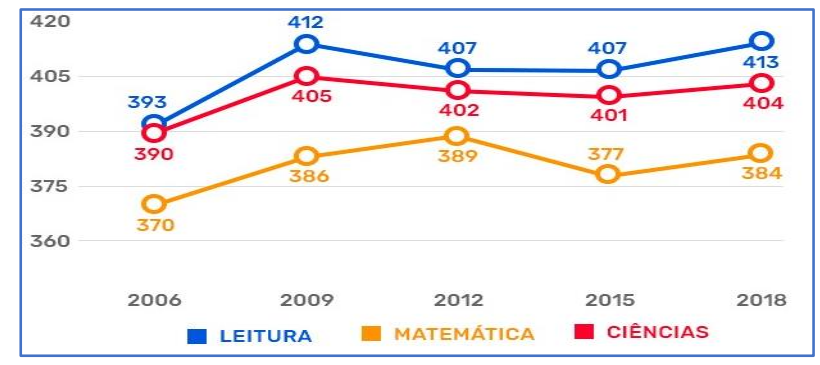

Fonte: INEP2 (2018).

Ressalta-se que esse indicativo se mantém estagnado desde 2009, conforme informações do INEP - Instituto Nacional de Estudos e Pesquisas Educacionais Anísio Teixeira, revelando uma realidade que precisa de iniciativas que busquem uma efetiva alteração desse cenário. A amostra que foi avaliada em 2018, 597 escolas públicas e privadas com 10.961 alunos, pertence a uma população de dois milhões de estudantes. Conquanto pareçam poucos participantes, não é difícil perceber esse baixo desempenho nas diversas unidades escolares brasileiras que apresentam dificuldades elementares de interpretação de textos (INEP, 2018).

Esse quadro representa, por exemplo, situações de incapacidade na compreensão textual, visto que os números do campo da leitura no Brasil podem ser comparados à média dos países da Organização para a Cooperação e Desenvolvimento Econômico (OCDE). As unidades escolares privadas e federais, com 510 e 503 pontos, considerada a margem de erro, apresentam índices superiores aos do Brasil, 413 pontos, em leitura e estão na média, que é de 487 pontos, dos países da Organização para a Cooperação e Desenvolvimento Econômico (OCDE). Os dois tipos de instituições de ensino também têm média bem acima das públicas estaduais e municipais, 404 e 330 respectivamente (INEP, 2018).

\footnotetext{
2 Disponível em https://desafiosdaeducacao.grupoa.com.br/pisa-2018-educacao-brasil/. Acesso em 24 maio. 2021.
} 


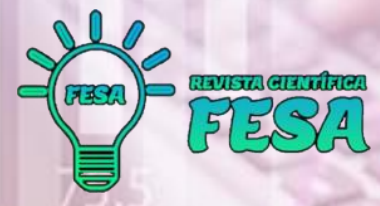

Observando essa situação pouco animadora em relação às habilidades leitoras nas escolas públicas de Educação Básica, os educadores devem sempre estar atentos a esse problema de amplitude nacional e perceber que o inventivo à leitura deve ser constante e um compromisso de todos os profissionais de educação, independentemente da sua área de atuação.

Em paralelo a esse incentivo, devem estar as novas teorias que parametrizam, de modo democrático, o ensino nas escolas. Como exemplo, temse a Aprendizagem Baseada em Projetos (ABP), ou Project Based Learning (PBL), denominada uma metodologia moderna que auxilia as unidades escolares e os docentes a lidarem, de forma eficiente, com os desafios oriundos da gerência educacional da atualidade. Esse método focaliza nas experiências vividas, possibilita uma maior participação dos estudantes ao longo o processo de aprendizado.

Dessa forma, o incentivo à leitura pode ser mediado com as diretrizes da Aprendizagem Baseada em Projetos (ABP), já que, como afirma Carleti (2007), a leitura é o meio mais importante para a aquisição de saberes na formação de um cidadão crítico para atuar na sociedade. Ainda, Cerqueira (2021) revela que:

[...] os professores [...] estão diante de novas perspectivas e de uma nova geração de alunos que tem um vasto acesso a tecnologias e informações e, assim, pode-se asseverar que as aulas [...] precisam de um novo formato, no qual o fazer docente seja contextualizado e voltado para as situações reais de utilização da língua (CERQUEIRA, 2021, p. 60).

Sobre a modernização do espaço escolar e o papel do docente nesse processo, Araújo e Xavier (2021) afirmam que:

[...] é necessário que as escolas façam mudanças pedagógicas para que os temas [...] sejam abordados com toda a sua riqueza, possibilidades e potencialidades, visto que, na educação contemporânea, o professor não é detentor do saber, sendo apenas mediador dos alunos ativos nos processos que participam e os conteúdos vão sendo construídos juntamente com toda equipe escolar (ARAÚJO; XAVIER, 2021, p. 53).

Portanto, a Aprendizagem Baseada em Projetos pode ser percebida como um guia para o trabalho em sala de aula, pautado na construção de conhecimentos por meio da realização de um projeto longo e contínuo de 
aprofundamentos, cujo escopo é atender a uma indagação, a um desafio ou a um problema.

Desse modo, o presente estudo tem a meta de relacionar a Aprendizagem Baseada em Projetos ao incentivo às práticas de leitura ao longo da Educação Básica com o aprofundamento das seguintes temáticas: Aspectos Essenciais da Aprendizagem Baseada em Projetos; Incentivo à Leitura no Espaço Escolar; Projetos de Leitura e ABP; e Considerações Finais.

\section{ASPECTOS ESSENCIAIS DA APRENDIZAGEM BASEADA EM PROJETOS}

Durante boa parte da história da educação, o método de ensino utilizado pelos docentes no espaço escolar seguiu as concepções tradicionalistas que concediam aos profissionais de educação uma maior segurança diante dos seus alunos, já que focava na reprodução de modelos reiteradamente testados e que, aos olhos da época, extremamente eficazes.

[...] no Ensino Tradicional a figura central é o professor com todos os seus atributos de detentor do saber, autoritário e inquestionável, que não proporciona aos seus alunos uma aula interativa e participativa, no Ensino Crítico todas essas descrições desaparecem, pois nesse modelo o educando se torna o centro do processo educativo e os professores mediadores do conhecimento, aqueles que apenas mostram caminhos para que o aluno por si só construa o conhecimento e de forma crítica possa refletir sobre o que está estudando (CORDEIRO, 2017, p. 27).

Com o passar do tempo, o perfil de alunos se modificou e o que era visto como ideal e adequado ficou ultrapassado. Os métodos de ensino tiveram de se adequar a esse perfil mais crítico e questionador que começou a surgir nas salas de aula. Diversos novos métodos surgiram, tendo em vista 0 universo multifacetado de estudantes presentes nas milhares de escolas espalhadas pelo mundo, já que nem sempre o que é eficaz para um público é, de igual maneira, eficaz para outro. Outro ponto de cisão dessa visão homogeneizante é o fato de cada componente curricular possuir demandas específicas e se enquadrar melhor em determinadas teorias.

Enfocando nesse movimento mais questionador, surgiu a Aprendizagem Baseada em Projetos (ABP) pensada para romper em definitivo com os paradigmas tradicionalistas do passado. Considerada uma metodologia ativa, a 
APB surgiu na década de 60 , no século passado, precisamente na Universidade de McMaster, no Canadá, a fim de atender à necessidade de estimular a aprendizagem do aluno com perfil mais proativo.

A ABP objetiva uma visão mais holística e ativa de ensino, no sentido de partir da prática para possibilitar a formação de um aluno mais ativo e disponibilizar o desenvolvimento de competências específicas ao longo desse processo. Assim, entende-se, tendo como parâmetro as ideias de Araújo (2019, p. 10), que a aprendizagem ativa é um processo em que se misturam conhecimentos, análise, pesquisas, estudos, trabalho em equipe, dentre outros, em que o docente se coloca num segundo plano, atuando como facilitador dentro desse processo.

Aprender via ABP torna-se mais significativo, uma vez que o ambiente interno de aprendizagem da academia se conecta com o ambiente externo dos processos sociais, políticos e ambientais por tarefas de aprendizagem "reais" e motivadoras (ARAÚJO, 2019, p. 11).

Com a meta de compreender como se estrutura a Aprendizagem Baseada em Projetos, torna-se necessário arrolar os elementos constitutivos para sua efetivação. O primeiro passo é definir o projeto, já que esse fornece o norte para o funcionamento de determinado componente curricular, por meio de âncoras pré-definidas pelos docentes ou pelos alunos, fornecendo espaço para o surgimento de problemas, oriundos de situações reais, dentro da estrutura do projeto (BENDER, 2014; NEUMANN et al, 2016).

Em seguida, conforme teoriza Bender (2014), tem-se a construção do processo que conta com algumas diretrizes: desenvolver a âncora do projeto; selecionar a questão motriz; processos específicos para a investigação e pesquisa; investigação e inovação dos alunos; cooperação e trabalho em equipe; e oportunidades para reflexão.

Em primeiro plano, há o desenvolvimento da âncora do projeto, que, geralmente, visa o engajamento dos estudantes para a execução da metodologia proposta, sendo importante destacar o viés criativo do docente para que se mantenha o interesse durante todo o processo. Na sequência, define-se a questão motriz, já que esses projetos são planejados para serem executados a 
longo prazo, sendo necessária a criação que uma problemática que se relaciona à âncora e promova a motivação do grupo (BENDER, 2014).

Em seguida, deve-se estabelecer os processos específicos para a investigação, com a inserção de estratégias metodológicas (mapas semânticos, vídeos de ensino, discussões em grupo) desenvolvidas pelos docentes para guiar e fornecer suporte teórico para os estudantes. Junto a esse movimento, há a investigação e a inovação dos discentes, cabendo ao professor facilitar, por meio da mediação, a criação de um ambiente de autonomia para os estudantes poderem buscar as respostas e inovar no alcance dos resultados (BENDER, 2014).

Ao lado desse inovar, deve estar a cooperação e o trabalho em equipe, pois a $A B P$ possibilita que as ações sejam trabalhadas em equipe para se alcançar um produto, permitindo uma vivência prática com o contexto atual. Há, por fim, as oportunidades para a reflexão que possibilitam perceber como foi produzido o conhecimento, fornecendo um resultado ainda mais significativo com um maior desenvolvimento de habilidades e um ambiente mais inovador (BENDER, 2014).

A definição de papéis também é um dos elementos constitutivos junto ao projeto e ao processo. O docente é dotado de uma postura mediadora, possibilitando, de acordo com Rodrigues-Sandoval et al (2010), com que os discentes atuem de modo independente. Bender (2014) acrescenta que deve haver um ensino estruturado, vídeos de ensino, palestras de convidados, discussões em grupo, registros em diários e mediação do professor. O resultado será a inserção, como relata Balsells et al (2012), de alunos mais protagonistas no processo de ensino-aprendizagem.

Por fim, há a avaliação que pode ser adequada ao tipo de trabalho desenvolvido, prescindindo de um modelo pré-determinado, entretanto despido do perfil tradicionalista do passado, focando, como assevera Uebe Mansur e Alves (2018) na avaliação por pares; dentro do seu grupo de forma mútua (alunoaluno) e no processo de evolução do projeto. Bender (2014) também inclui o uso de rubricas, como um guia de avaliação que traz pontuações a partir de critérios específicos para mensurar o desempenho e a autoavaliação reflexiva que permite que os alunos melhorem o trabalho ao longo do tempo e consigam expor suas percepções sobre o que foi desenvolvido. 


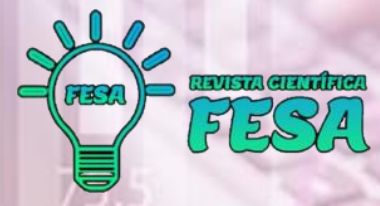

Assim, a ABP possibilita um resultado positivo no trabalho em sala de aula, pois contribui para o aprimoramento de habilidades e de competências, já que promove a relação entre teoria e prática. Entende-se, ainda, que a ABP conjuga a teoria abordada em sala com as questões motrizes propostas, pois exige a atuação de equipes com papéis definidos inclusive a função de liderança que pode ser compartilhada.

\section{INCENTIVO À LEITURA NO ESPAÇO ESCOLAR}

Tendo como base as teorias concernentes à ABP, faz-se necessário detalhar a outra unidade de análise, a leitura. Consoante com Martins (1994, p. 23), a leitura se realiza a partir do diálogo do leitor com o objeto lido, seja ele escrito, sonoro, um gesto, uma imagem, um acontecimento, ou seja, é o ato de ler, atribuindo sentido aos diversos textos existentes por meio da capacidade humana de interpretação.

Seria preciso, então considerar a leitura como um processo de compreensão de expressões formais e simbólicas, não importando por meio de que linguagem. Assim, 0 ato de ler se refere tanto a algo escrito quanto a outros tipos de expressão do fazer humano, caracterizando-se também como acontecimento histórico e estabelecendo uma relação igualmente histórica entre leitor e o que é lido (MARTINS, 1994, p. 30).

Atrelada à concepção de leitura, há o lado prático e empírico imanente à sua definição. A palavra leitura pode ser considerada uma ação, tendo em vista que se materializa no ato de ler. Sem um objeto a ser interpretado, não há leitura, ou seja, ela só existe diante de práticas de leitura. Para se manter em ação esse conceito, deve-se sempre estimular e incentivar essas práticas, sendo o espaço escolar prototipicamente ideal para esse fim. Kleiman (2011) aborda essa questão da efetividade e do sentido da leitura ao abordar questões relativas à construção do conhecimento.

[...] o conhecimento linguístico, o conhecimento textual, o conhecimento de mundo devem ser ativados durante a leitura para poder chegar ao momento de compreensão, momento esse que passa desapercebido, em que as partes discretas se juntam para fazer um significado. O mero passar de olhos não é leitura, pois a leitura implica uma atividade de procura por parte do leitor, no seu passado, de lembranças e conhecimentos, daqueles que são relevantes para a 
compreensão de um texto que fornece pistas e sugere caminhos (KLEIMAN, 2011, p. 26).

Em contrapartida, diante de um mundo tão multifacetado e permeado de diversos estímulos tecnológicos, os docentes têm de se reinventar para fornecer estímulos para a construção do hábito de ler.

A função do educador não seria precisamente a de ensinar a ler, mas a de criar condições para o educando realizar a sua própria aprendizagem, conforme seus próprios interesses, necessidades, fantasias, segundo as dúvidas e exigências que a realidade the apresenta. Assim, criar condições de leitura não implica apenas alfabetizar ou propiciar acesso aos livros. Trata-se, antes, de dialogar com o leitor sobre sua leitura, isto é, sobre o sentido que ele dá, repito, a algo escrito, ideias, situações reais ou imaginárias (MARTINS, 1994, p. 34).

Assim, esse incentivo à leitura deve ser intencional e planejado, pautado em teorias modernas que considerem o alunado inserido em uma sociedade que possui questões mais amplas e que são passíveis de críticas e questionamentos. O educador deve partir dos conhecimentos prévios dos próprios alunos (SOLÉ, 1998) para atribuir significado e importância ao que se coloca em questão.

O ensino inicial da leitura deve garantir a interação significativa e funcional da criança com a língua escrita, como meio de construir os conhecimentos necessários para poder abordar as diferentes etapas da sua aprendizagem. Isso implica que o texto escrito esteja presente de forma relevante na sala de aula - nos livros, nos cartazes que anunciam determinadas atividades[...] (SOLÉ, 1998, p. 62).

Somado a isso, segundo Gosztonyi (2012), há a criticidade natural que surge a partir das práticas de leitura.

A leitura possibilita o surgimento de seres humanos mais críticos e mais questionadores. Também nos capacita a atingir às necessidades competitivas do mercado, possuir maior habilidade de diálogo e lutar por um ideal. Só poderemos entrar nesta nova direção se buscarmos o conhecimento de forma contínua e exploratória. Quanto mais conhecemos, mais nos motivamos a conhecer (GOSZTONYI, 2012, p. 18). 


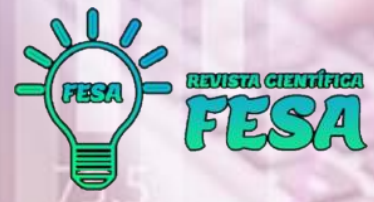

Portanto, evidencia-se que, à medida que a leitura é incentivada, os indivíduos mostram-se mais conhecedores de si mesmos, com mais vontade de aprender e com uma curiosidade maior de compreender o seu entorno. Assim, o incentivo à leitura é algo que precisa ser levado em discussão, sendo imprescindível a necessidade de acompanhar esse desenvolvimento, observando sempre seu crescimento e a forma pelo qual está sendo executado. Finalizando com as concepções de Smith (1999, p. 15), o hábito de leitura não pode ser ensinado, mas conduzido, e, apesar disso, os professores e outros adultos têm um papel decisivo a desempenhar e é deles a grande responsabilidade de tornar possível a aprendizagem da leitura.

\section{PROJETOS DE LEITURA E ABP}

A fim de atender ao objetivo dessa investigação, relacionar a Aprendizagem Baseada em Projetos ao incentivo às práticas de leitura ao longo da Educação Básica, pretende-se unir a $\mathrm{ABP}$ e o incentivo à leitura para fornecer mais recursos aos professores de Educação Básica na atuação em sala de aula.

As práticas de leitura na Educação Básica são basilares para preparar os alunos para agirem em prol de suas ações no futuro. Essas ações também são imprescindíveis para os estudantes, pois a leitura vai fazer parte, naturalmente, do seu exercício como cidadão.

Acerca da função social, Fischer (2007, p. 29) postula que o uso da leitura está ligado ao meio social, sendo situado e histórico, já que "a condição letrada de um sujeito, em um situado espaço da sociedade e em particular momento histórico de sua trajetória pessoal e social".

Retomando Kleiman (2005) e alinhando com Fisher (2007), nota-se que as práticas de uso da leitura e escrita são sempre práticas situadas e, conforme assevera Bartlett (2007), tais práticas são dotadas de leitura em inúmeros contextos, destacando-se as formas linguísticas multimodais assim como o uso das tecnologias para a leitura e produção de textos. Em acréscimo, para as autoras Vóvio e Souza (2005), as práticas de leitura são delimitadas por configurações singulares, relacionadas com as histórias de vida, das práticas e atividades de que os sujeitos tomam parte em seu cotidiano, limitadas aos 
grupos sociais a que pertencem e à atividade a que se dedicam, bem como ao contexto sócio - histórico (VÓVIO; SOUZA, 2005).

Tendo em vista essa situatividade inerente às práticas de leitura é de se esperar que a ABP seja ideal para o desenvolvimento de habilidades que fomentem o ato de ler, visto que busca desafiar os alunos na busca de soluções inovadoras que produzam melhorias na sociedade.

[...] a leitura e escrita são práticas sociais, que variam de acordo com contexto, cultura e gênero, sendo vistas como práticas associadas a diferentes comunidades. Esse enfoque prevê a relação do estudante com a leitura e a escrita pelas crenças, os valores e a ideologia da cultura dos grupos sociais, fazendo com que relacione os sentidos sociais das disciplinas e dos conteúdos, de acordo com as práticas sociocomunicativas a que esteja exposto (LEA; STREET, 2006 apud DE MATOS THEISEN et al, 2016, p. 3)

Assim, entende-se que a escola precisa elaborar e pôr em prática estratégias que auxiliem os alunos a crescerem em relação às competências sobre às ações voltadas para a leitura, dando ênfase aos conhecimentos que os estudantes trazem consigo, na medida em que, conforme Kleiman (2005), percebe-se que as práticas de leitura podem auxiliar o aluno a aprender mais sobre o conteúdo que está estudando. Feito isso, a ABP contribui de modo muito efetivo nesse processo de desenvolvimento e aprimoramento de habilidades e competências linguísticas, visto que envolve um trabalho em equipe que é formado por um grupo pequeno de pessoas, com objetivos e compromissos comuns para atingir determinada meta (KATZENBACH; SMITH, 1994).

Atrelar a leitura e a ABP requer muito planejamento por parte dos professores e a cuidada seleção dos objetivos a serem alcançados, pois as práticas de aprendizagens significativas devem estar relacionadas à realidade social que, por dotar de natural situatividade temporal, deve estar em constante atualização. Assim, a ABP, de acordo com De Matos Theisen (2016), pode auxiliar os estudantes a vivenciarem situações reais de aprendizagem, destacando que dois elementos são comuns na ABP, o primeiro é a participação ativa do estudante; e, segundo, são os problemas colocados para os estudantes resolverem, bem próximos da realidade. 
Dessa forma, a ABP auxilia os alunos, pois os insere em questões da realidade, exigindo tomada de decisões, estabelecimento de posições, processos de organização, aprimoramento da criticidade e, principalmente, o planejamento em grupos com compartilhamento da liderança, inclusive. A metodologia $A B P$ ganha mais espaço e relaciona-se intimamente com uma perspectiva sociocultural dos estudos linguísticos, abarcando a teoria e a prática, e possibilitando uma aprendizagem significativa. Nota-se que o trabalho em grupo demanda muita reflexão e diferentes modos de agir dentro da equipe.

\section{CONSIDERAÇÕES FINAIS}

Com base nos constructos desenvolvidos até este ponto, fica claro que a ABP aliada à leitura possibilita a execução de atividades em grupos de modo que seus integrantes sejam capazes de interpretar a realidade, tendo como base o desenvolvimento de competências necessárias, neste caso, para o desenvolvimento do hábito de leitura, dentro e fora do espaço escolar.

Percebe-se a necessidade de se seguir as etapas da ABP, tais como 0 desenvolver a âncora do projeto; a definição da questão motriz; o planejamento dos processos específicos para a investigação e pesquisa; a realização de ações de investigação e de inovação por parte dos alunos; desenvolver a cooperação e o trabalho em equipe; e deixar oportunidades para reflexão.

Dessa forma, o hábito pela leitura será construído de modo natural e paralelo à percepção de questões sensíveis da realidade, ampliando a capacidade de interpretação, que é interessante para todas as áreas do conhecimento, a fim de se elevar os índices que medem a capacidade leitora dos estudantes brasileiros.

\section{REFERÊNCIAS BIBLIOGRÁFICAS}

ARAÚJO, H. S. V. R. Aprendizagem Baseada Em Projetos: aplicação nas disciplinas de Organização e Métodos e Gestão da Qualidade e Produtividade no curso de Administração. Trabalho de Curso apresentado ao Centro de Ciências Sociais Aplicadas, da Universidade Federal da Paraíba / UFPB, 2019. Disponível em: https://repositorio.ufpb.br/ispui/bitstream/123456789/16221/1/HS VRA311 02019.pdf Acesso em 25 mai. 2021. 
ARAÚJO, D. da S.; XAVIER, E. D. de S. Educação Financeira e a linguagem: uma proposta transversal a partir do gênero textual fábula. Revista Científica FESA, [S. I.], v. 1, n. 2, p. 50-63, 2021. DOI: 10.29327/232022.1.2-4. Disponível em: https://revistafesa.com/index.php/fesa/article/view/12. Acesso em: 24 maio. 2021.

BALSELlS, M. A. C.; CHAMORRO, V. A. P.; PEREA, J. G. A. DE. Aprendizaje basado en proyectos y trabajo en equipo: innovando en la docencia de la asignatura sistemas contables informatizados. Revista de Innovación Docente, vol. I, Sevilla, Espanha, 2012.

BARTLETT, L. To seem and to feel: situated identies and literacy practices. Teachers College Record. Columbia University, v. 109, n. 1, p. 51-69, january 2007.

BENDER, W. N. Aprendizagem Baseada em Projetos: educação diferenciada para o século XXI. Porto Alegre: Penso, 2014.

CARLETI, R. C. A leitura: um desafio atual na busca de uma educação globalizada. ES, 2007. Disponível em http://www.univen.edu.br/revista. Acesso em maio de 2021.

CERQUEIRA, J. B. de S. Material didático: recursos para o aprimoramento do ensino de língua portuguesa à luz da cognição. Revista Científica FESA, [S. I.], v. 1, n. 1, p. 59-78, 2021. Disponível em: https://revistafesa.com/index.php/ fesa/article/view/5. Acesso em: 24 maio. 2021.

CORDEIRO, K. C. L. V. Ensino tradicional $\mathbf{x}$ ensino crítico: desafios $\mathbf{e}$ problemas Metodológicos do ensino de história na escola estadual Frei André da Costa. Monografia apresentada à Coordenação do Curso de História da Universidade do Estado do Amazonas, 2017. Disponível em: http://repositorioinstitucional.uea.edu.br/bitstream/riuea/836/1/Ensino\%20Tradic ional\%20x\%20Ensino\%2 $0 \mathrm{Cr} \% \mathrm{C} 3 \%$ ADtico\%20desafios\%20e\%20problemasMetodol\%C3\%B3gicos\%20do\%20Ensino\%20 de\%20Hist\%C3\%B3ria\%20na\%20Escola\%20Estadual\%20Fr ei\%20Andr\%C3\%A9\%20da\%20Costa.pdf Acesso em: 25 mai. 2021.

DE MATOS THEISEN, J.; ALVES, A.; VAN HATTUM-JANSSEN, N. Práticas de leitura e escrita no trabalho em equipas na Aprendizagem baseada em Projetos. Project Approaches in Engineering Education, 2016. Disponível em https://scholar.google.com.br/scholar?cluster=10816921969898228481\&hl=ptBR\&as_sdt=0,5 Acesso em 25 maio 2021. 
GOSZTONYI, R. T. A importância de incentivo à leitura. INEP, 2012.

FISCHER, A. A construção de letramento na esfera acadêmica. Tese (Doutorado) Universidade Federal de Santa Catarina. Florianópolis, 2007.

KATZENBACH, J. R.; SMITH, D. K. A Força e o Poder das Equipes. São Paulo: Makron, 1994.

KLEIMAN, A. Texto e Leitor: aspectos cognitivos da leitura. 14. ed. São Paulo: Pontes, 2011.

LEA, M. R.; STREET, B. V. The academic literacies model: theory and applications. Theory into Practice. v. 4, n. 45, p. 368-377, 2006.

MARTINS, M. H. O que é leitura. 19. ed. São Paulo: Brasiliense, 1994.

NEUMANN, S. E.; BORELLI, V. A.; OLEA, P. M. Aprendizagem Baseada em Projetos no Curso de Administração: Um Estudo de Caso em uma Instituição de Ensino da Serra Gaúcha. XVI Mostra de Iniciação Científica, Pós-Graduação, Pesquisa e Extensão, Caxias do Sul, Rio Grande do Sul, 2016.

RODRIGUEZ-SANDOVAL, E.; VARGAS-SOLANO, É. M.; LUNACORTES, J. Evaluación de la estratégia "aprendizaje basado en proyectos". Educ. Educ., v.13, n 1, p. 13-25, 2010.

SMITH, F. Leitura Significativa. 3. ed. Porto Alegre: Artes Médicas, 1999.

SOLÉ, I. Estratégias de leitura. 6. ed. Porto Alegre: Artimed, 1998.

UEBE MANSUR, A. F.; ALVES, A. C. A importância da avaliação por pares e autoavaliação em ABP aplicada a um curso de Administração. RIAEE Araraquara, v. 13, n. esp1, p. 456-473, 2018.

VÓVIO, C. L.; SOUZA, A. L. S. Desafios metodológicos em pesquisas sobre letramento. In: KLEIMAN, A.; MATÊNCIO, M. L.(orgs.) Letramento e formação do professor. Campinas: Mercado de Letras, 2005. p. 41-64. 